\title{
Scientific bases of innovative development of agrarian economic entities: a cluster approach
}

\author{
Sergey Butorin ${ }^{1, *}$ \\ ${ }^{1}$ Perm State Agro-Technological University named after Academician D. N. Pryanishnikov, \\ Petropavlovskaya str., 23, Perm, Russia
}

\begin{abstract}
In the situation of globalization of the world economy, the nature of development of all sectors of the economy, including the agrarian sector, is inextricably linked with active innovation activity. As the foreign and already Russian experience of high-tech sectors of the economy shows, business entities achieve opportunities for innovative development through the involvement of stakeholders (subcontractors, suppliers and consumers) in setting up joint ventures and products, combining economic activities with the goal of more effective joint strategic development. Today, these are agro-clusters, in which both branches of integration of large (including agricultural holdings), and medium and small forms of management are possible, while preserving their legal and economic independence, with legislative and financial support of the state (publicprivate partnership), should be considered the most promising form of associations of economic entities.
\end{abstract}

\section{Introduction}

Import substitution with the subsequent transition to export-oriented activity of economic entities is one of the most important tasks in modern conditions of development of the agrarian sector of the Russian economy. However, the solution of this issue is currently conditioned not so much by the introduction of economic sanctions against Russia, as by the non-competitiveness of the majority of economic entities in the agrarian sector of the Russian economy, which led to a significant increase in the demand for foodstuff imports. The solution of this task should be considered in direct connection with the innovative development of economic entities in the agricultural sector of the economy. The latter is related to the fact that strengthening competition, both on external and internal markets, makes business entities seek and implement more and more innovative solutions, not only in the technological sphere, but also in social, economic, environmental and institutional ones.

In order to increase the activity of economic entities to innovation activity as a tool for ensuring the effectiveness of the use of external and internal competitive advantages in the context of uncertainty and high dynamism of changes in the innovation economy, it is necessary to promote the processes of uniting economic entities into integration groups that

* Corresponding author: butorinsergey@yandex.ru 
specialize in adapting them to dynamic changes in the external environment and optimizing the use of internal resources in order to produce competitive products.

\section{Results}

For modern conditions in the agrarian sector of economies of the developed countries are typical the following phenomena:

- Innovative character of the agricultural sector of the economy;

- Accelerated development of logistics and transport infrastructure, while natural, territorial, and resource benefits lose their former role;

- The development of market infrastructure, including Internet technologies, when the formation of electronic trading platforms does not allow enterprises to receive super-profit, based on the conjuncture factors and the lack of reliable information about the market;

- Commercialization of the production, technological and innovation spheres, which makes production technology and equipment more accessible to a wide range of consumers.

The current stage of development of the agricultural sector is characterized by intellectualization ("smart" farming), automation and robotization of agricultural labor.

According to the Beecham Research report, in the near future "smart" farming will allow agricultural producers to increase yield and cut costs - from the amount of fertilizers used and to the number of trips on farm machines. The report notes that the ecosystem of suppliers and stakeholders is very complex. It includes a huge number of participants, ranging from large manufacturers of heavy agricultural machinery, and to suppliers of M2M technology (inter-machine technology) and IT support of decision-making systems, as well as providers of experience and knowledge in all areas of the farming. In this case partnership is the key factor in creating a successful supply chain [1].

Market research shows that some of the largest application segments will include unmanned aerial vehicles (UAVs) for agricultural purposes, soil robots, materials application robots, driverless tractors and milking robots in dairy farms. According to the forecasts of Tractica, the international market for agricultural robots will increase from 3.0 billion dollars in 2015 to 73.9 billion dollars by 2024 . Among the types of robots used for agricultural purposes, the sales of driverless tractors will be the largest ones (up to 30.7 billion dollars by 2024), and agricultural UAVs (Drones) will be the most common in terms of supply units (up to 411,000 pieces by 2024) [15].

The above tendencies of the development of the agricultural sector abroad indicate a gradual reorientation of the agrarian economy to the innovative path of development, when innovations play the key role in economic activity. In this regard, it is necessary to form such economic entities, within which conditions and opportunities for generating new knowledge and skills will be created, and the opportunity for full-fledged innovation activity for all or most economic entities of the agricultural sector of the economy will be ensured. The most effective among such formations, as follows from the global and already emerging Russian practice, are clusters and, in particular, agro-clusters $[2,3,4,5,6,7]$.

At the same time, it is necessary to understand that there is a variability of cluster integration formations, determined by the main purpose of creating a cluster. So, for example, as shown in the work of O.A. Myzrova and L.V. Slavnetskov, there may be the following types of cluster formations [8]:

1) An infrastructure-innovation cluster. It is formed around the system of guaranteed consumption of products. The existing infrastructure is used, but new technological solutions are applied;

2) An innovative cluster. It is formed on the basis of a fundamentally new, non-existent infrastructure; its formation provides for the state guarantees; 
3) An ultrastructural (meta-industrial) cluster. It is formed on the basis of transformations of the agro-industrial complex. Herewith, an advanced technology is created, within which agro-industrial and related enterprises are formed;

4) A "borrowed" cluster. It is formed on the basis of foreign experience of the applied technologies and is based on import substituting technologies.

For the agrarian sector, in the conditions of low innovation activity (Table 1), on the one hand, and a sufficiently high level of profitability of economic entities, formed in recent years (Table 2), on another hand, the agro-cluster integration formation should solve two main problems impeding the transition of the agrarian sector on the innovative path of development [9].

Table 1. The share of agricultural organizations, peasant farms and individual entrepreneurs using innovative technologies, according to All-Russian agricultural census 2016, \% [16].

\begin{tabular}{|l|c|c|}
\hline \multicolumn{1}{|c|}{ Innovation technologies } & $\begin{array}{c}\text { Agricultural } \\
\text { organizations* }\end{array}$ & $\begin{array}{c}\text { Peasant farms and } \\
\text { individual } \\
\text { entrepreneurs }\end{array}$ \\
\hline Integrated irrigation system & 4.7 & 3.7 \\
\hline $\begin{array}{l}\text { Biological methods of plant protection from pests and } \\
\text { diseases }\end{array}$ & 10.3 & 9.3 \\
\hline Individual feeding system & 8.1 & 4.7 \\
\hline Methods of biological poultry & 1.5 & 1.6 \\
\hline Wastewater treatment plants on livestock farms & 4.8 & 1.2 \\
\hline Wastewater removal and treatment system & 9.9 & 3.7 \\
\hline Renewable energy sources & 1.9 & 1.8 \\
\hline $\begin{array}{l}\text { Accurate driving and diagnostic quality control system of } \\
\text { technological processes }\end{array}$ & 7.1 & 0.8 \\
\hline
\end{tabular}

* - excluding the non-agricultural plots of agricultural enterprises organizations.

Table 2. Profitability of agricultural organizations in the agrarian sector of the Russian economy, in percent [17].

\begin{tabular}{|c|c|c|c|c|c|c|}
\hline Indicators & 2011 & 2012 & 2013 & 2014 & 2015 & 2016 \\
\hline Profitability of agricultural organizations, \% & 11.8 & 12.1 & 7.3 & 16.1 & 20.3 & 16.4 \\
\hline
\end{tabular}

Firstly, this the integration of small, medium-sized and large economic entities, while preserving their legal and economic independence, in order to confront crisis phenomena and ensure organizational changes aimed at the integration and joint development of agricultural producers, services, consumer cooperation and processing. [10] Secondly, due to the network nature of interaction within the framework of the integration formation, such a significant problem as the gap between the available knowledge and the tasks of innovative development of the agricultural sector should be solved [11]. Solving these issues in aggregate will form the demand for innovations and, thereby, create favorable conditions for the implementation of innovative activities in the agricultural sector of the economy.

Foreign experience shows that in order to stimulate the introduction of innovative technologies, first of all, people, processes and the environment (place) are needed. Employees must have the necessary skills and mentality. Managers who know how to generate ideas and how to turn them into really working technologies will be required. Before business entities become more innovative-oriented, it is necessary to create conditions for that and provide support from relevant, innovative-oriented units, specially created for this purpose $[12,13,14]$. 


\section{Discussion}

It is possible to consider the business-dominant agro-cluster of the milk-grocery subcomplex of Perm territory as an example of the agro-cluster as a specialized integration formation intended for the development of its economic entities.

Dairy and commodity direction was chosen as a priority in the Perm territory for implementing cluster initiatives in connection with the existence of stable common economic interests of economic entities of the dairy products sub-complex, determined, for the most part, by the conditions of acute interregional competition with producers, both raw milk and products of milk processing, from the Udmurt and Bashkir republics and the Kirov region. It is consisting of:

1) Expansion of the volume of production of goods;

2) Implementation of a unified marketing policy;

3) Introduction of innovative technologies, as a result of integration and cooperation of production of goods and their sales on the commodity markets.

A group of enterprises consisting of "Nytvenskii Butter Plant" Open Company (production capacity 250 tons per shift), Open Company "Yugovskii Dairy Plant" (production capacity 450 tons per shift) and 64 agricultural producers of the Perm territory can be considered as one of such agro-clusters, which corresponds to the main features of the cluster formations:

1) Joint long-term innovative development;

2) Voluntary entry;

3) Equivalence of income and costs;

4) Legal independence of participants;

5) Orientation on synergetic effect from the joint activity;

6) Mutual control and overall strategic management.

The strategic goal of this and other agro-cluster formations existing in the Perm territory is to ensure the sustainable competitiveness of the dairy cattle breeding by creating a modern management system for the balanced development of economic entities of the dairy product sub-complex of the region.

The key directions of the strategy of sustainable competitiveness of dairy farming in the Perm territory selected in the dairy cluster are as follows:

1) Innovative systems for feeding and maintaining animal health (use of modern effective and environmentally friendly probiotics, feed additives, immunostimulants);

2) Effective utilization of animal by-products;

3) Product quality assurance - organizational work in fodder production, compliance with the technology of growing and keeping animals;

4) Continuous breeding work;

5) Production of ecologically safe livestock products;

6) Minimizing the impact of production on the environmental objects;

7) Saving labor and energy resources, rationalizing the use of resource potential.

Interviewees from the Perm State Agrarian Technical University, Perm Scientific Research Institute of Agriculture and the Ministry of Agriculture and Foodstuffs of the Perm territory identified the following advantages of agro-cluster integration formations in the dairy products sub-complex of the Perm territory [18]:

1) Technical and technological innovations are provided due to which the growth of labor productivity in agricultural production in the medium- and long-term perspective takes place in comparison with the agricultural producers isolated from the association;

2) New high-tech jobs are being opened;

3) There is an increase in the volume of commodity deliveries to the market; 
4) Savings are achieved on the scale of purchases of raw materials, machinery, technologies and construction works for the development of additional production capacities;

5) There is an increase in the taxable base in the region;

6) Targeted cooperation with educational institutions is being formed.

Separately, such an advantage has been singled out as a common marketing activity that contributes to the effective search for new markets for dairy products, which is also realized through the priority regional approach "BUY PERM".

Estimating the five-year period since the beginning of the implementation of these agrocluster initiatives in the Perm territory, it is possible to conclude that they have produced good results for the development of economic entities. The development of agricultural organizations involved in cluster formations led to an increase in the number of cows, in the productivity of cows and in labor productivity. All this led to a growth of self-sufficiency in milk and dairy products in the Perm territory, which increased from 65.9\% in 2012 to $71.6 \%$ in 2016 (Table 3).

Steady growth of these indicators is ensured through unified coordinated technological work and strategic management of the production and sales, R\&D and innovative activities, delegated to managing structures within the framework of the agro-cluster integration formation.

Table 3. Indicators of development of economic entities of the dairy product sub-complex in the Perm territory [19].

\begin{tabular}{|l|c|c|c|c|c|c|c|}
\hline \multicolumn{1}{|c|}{ Indicators } & 2012 & 2013 & 2014 & 2015 & 2016 & $\begin{array}{c}2017 \\
\text { (forecast) }\end{array}$ & $\begin{array}{c}2017 \\
\text { in \% } \\
\text { to } \\
2012\end{array}$ \\
\hline $\begin{array}{l}\text { Number of cows, thousand } \\
\text { heads }\end{array}$ & 73.2 & 72.0 & 72.3 & 74.1 & 74.8 & 75.2 & 102.7 \\
\hline $\begin{array}{l}\text { Productivity of cows, kg / } \\
\text { head }\end{array}$ & 5072 & 5008 & 5411 & 5612 & 5840 & 5960 & 117.5 \\
\hline $\begin{array}{l}\text { Labor productivity, thousand } \\
\text { rubles / person }\end{array}$ & 589.8 & 619.2 & 797.7 & 985.4 & 1095.2 & 1150.3 & 195.0 \\
\hline $\begin{array}{l}\text { Self-sufficiency in milk and } \\
\text { dairy products, } \%\end{array}$ & 65.9 & 66.3 & 67.8 & 70.3 & 71.6 & 74.9 & $\mathrm{X}$ \\
\hline
\end{tabular}

A complex task that must be solved when moving to work in the format of an agrocluster integration formation, considering that all or most of the participants retain their legal status and financial independence, is the optimal distribution of powers to manage innovation development.

To solve this problem, a list of the main functions of the agro-cluster integration formation for managing the innovative development of economic entities has been formed (Table 4).

Table 4. The functions of the agro-cluster innovative formation for managing the innovative development of economic entities. Source: research results of S.N. Butorin.

\begin{tabular}{|l|l|}
\hline$№$ & \multicolumn{1}{|c|}{ Function } \\
\hline 1. & $\begin{array}{l}\text { Generalization of information on regulatory and legal regulation in the field of innovative } \\
\text { development }\end{array}$ \\
\hline 2. & $\begin{array}{l}\text { Development of a project of innovative measures to ensure a balanced functioning of } \\
\text { economic entities participating in the agro-cluster formation }\end{array}$ \\
\hline 3. & Forming a road map for introducing innovations agreed with economic entities \\
\hline
\end{tabular}




\begin{tabular}{|l|l|}
\hline № & \multicolumn{1}{|c|}{ Function } \\
\hline 4. & Developing a system of motivating business entities for innovative activity \\
\hline 5. & $\begin{array}{l}\text { Organization of training and development of personnel of economic entities considering the } \\
\text { plan for introducing innovations, also taking into account bottlenecks in the competence of } \\
\text { employees }\end{array}$ \\
\hline 6. & $\begin{array}{l}\text { Organization and participation in competitions of innovation projects of district and regional } \\
\text { levels }\end{array}$ \\
\hline 7. & Formation of information databases on innovations and their actualization \\
\hline 8. & $\begin{array}{l}\text { Monitoring of economic entities with best practices that are not part of the agro-cluster } \\
\text { integration formation, the establishment of information exchange }\end{array}$ \\
\hline 9. & $\begin{array}{l}\text { Organization of communication with scientific organizations, educational institutions and } \\
\text { consulting services }\end{array}$ \\
\hline 10. & $\begin{array}{l}\text { Search for the most optimal innovations for economic entities and assessment of their } \\
\text { efficiency }\end{array}$ \\
\hline 11. & $\begin{array}{l}\text { Preparation of model of innovative projects and their coordination with the management of } \\
\text { business entities }\end{array}$ \\
\hline 12. & $\begin{array}{l}\text { Participation in the implementation of innovative projects and monitoring the progress of this } \\
\text { process against the basic parameters of the project }\end{array}$ \\
\hline 13. & $\begin{array}{l}\text { Organization of funding innovative projects and performing functions of a guarantor and co- } \\
\text { investor }\end{array}$ \\
\hline
\end{tabular}

Perhaps, in due course, when a strong network of state structures of innovative development is created in the agrarian sector, the need for the creation of agro-cluster integration formations as managers of innovative development of economic entities will disappear, and their functions will be fully taken over by consulting services. At present, as the experience of the Perm territory shows, the need for the creation and development of agro-cluster integration formations remains.

Increasing role of the management bodies of agro-cluster integration units in managing the innovative development of economic entities will require an increase in the costs for performing these functions. Having studied the market of innovative consulting and research and development services in the field of agribusiness, we have calculated the annual competitive level of income and additional costs for compensating the activities of one specialist in this field (Table 5).

Making these additional costs, it is necessary to understand that investments in innovative development pay off quickly, especially with such a low level of efficiency of activities, which now have many business entities. This is confirmed by the indicators of development of economic entities of the dairy product sub-complex of the Perm territory, presented in this study.

Table 5. Calculation of the annual competitive level of income and additional costs for the compensation of work of one specialist in the sphere of innovative development.

\begin{tabular}{|l|c|}
\hline \multicolumn{1}{|c|}{ Motivation component } & $\begin{array}{c}\text { Value of the } \\
\text { component, } \\
\text { thousand rubles per } \\
\text { year }\end{array}$ \\
\hline Salary & 600 \\
\hline Bonuses (annual and project remuneration based on performance) & 350 \\
\hline Training and career development & 30 \\
\hline Voluntary health insurance & 10 \\
\hline Housing program & 100 \\
\hline
\end{tabular}




\begin{tabular}{|l|c|} 
Corporate service (official transport, communications, AWP, etc.) & 50 \\
\hline $\begin{array}{l}\text { Corporate and social events for employees and their children (rest during } \\
\text { vacation, New Year's gifts, professional holidays) }\end{array}$ & 80 \\
\hline Security system (including normative working conditions in the workplace) & 20 \\
\hline Pension program & 10 \\
\hline Total direct costs: & 1250 \\
\hline Deductions to insurance funds: & 286.9 \\
\hline Total: & 1536.9 \\
\hline
\end{tabular}

Source: compiled by the authors.

\section{Conclusion}

Agro-cluster as an integration formation of development of economic entities implies an increase in the efficiency of the transfer of innovations to business entities. Transfer of innovative technologies is carried out taking into account the features of production capacities and mutual adaptation of production and economic complexes within the framework of the agro-cluster, considering the common purpose of its creation. This allows achieving the following results:

1) To form a stable competitiveness of the agro-cluster as an industrial and commercial structure;

2) To increase the consolidated value of economic entities and, accordingly, their credit and investment attractiveness;

3) To create effective mechanisms for the modernization of production capacities and the reproduction of the technical potential of economic entities within the framework of the agro-cluster.

\section{References}

1. BeehamResearch, Towards smart farming: Agriculture embracing the IoT Vision (Beecham Research Limited, London, 2015)

2. L.V. Shchukina, Bulletin of Gomel State Technical University, 3 (2014).

3. N. V. Borovskikh, Agriculture in the modern economy: a new role, growth factors, risks (VIAPI RAAS, Moscow, 2009)

4. V. A. Kundius, A.V. Glotko, A. V. Sibiryakov, A. M. Kudinova, Economic strategy and mechanisms of innovation-cluster development of the region's agroindustrial complex (ASAU, Barnaul, 2008)

5. M. E. Porter, Economic Development Quarterly, 14, (2000)

6. C. Ketels, G. Lindqvist, O. Solvell, The Cluster Observatory, 56 (2012)

7. European Committee of the Regions, Clusters and clustering policy: a guide for regional and local policy makers (ECR, Brussels, 2010)

8. O. A. Myzrova, L. V. Slavnetskova, Bulletin of the Saratov State University - New Series - Ecomomics, Managementm Law, 16, 1 (2016)

9. S. N. Butorin, Theory and methodology of innovation-oriented management in agribusiness (VNIIESH, Moscow, 2017). 
10. S. N. Butorin, Scientific Review, 22 (2016)

11. S. N. Butorin, A. V. Bogoviz, AIC: Economics, Management, 12 (2017)

12. R. Baumruk, Workspan, 47 (2004)

13. M. Hekkert, S. Negro, Technological Forecasting and Social Change, 74, 4 (2009)

14. S. Voelpel, M. Leibold, C. Streb, Journal of Change Management, 5, 1 (2007)

15. Tractica, Driverless tractors and drones to be among the key applications for agricultural robots (Tractica, Boulder, 2016)

16. A. V. Petrikov, Results of the All-Russian Agricultural Census of 2016: changes in Russian agriculture over the past 10 years (RIA Novosti, Russia, 2017)

17. Data obtained from Rosstat (www.gks.ru) and Ministry of Agriculture of the Russian Federation (www.mcx.ru)

18. Department of Production \& Entrepreneurship, Report on research work on the topic "Improving economic relations in the market system of forms of management of the agrarian and industrial complex of the Perm Krai" (PSATU, Perm, 2018)

19. Data of the Ministry of Agriculture and Food of the Perm Region (www.agro.permkrai.ru) 